\title{
Effect of vitamin D supplementation and magnesium sulfate therapy in pre-eclampsia
}

\section{Neeru Bhaskar, Harnam Kaur, Sheikh Ishaq, Ruhi Mahajan, Qazi Najeeb}

Department of Biochemistry, Maharishi Markandeshwar Institute of Medical Sciences and Research, Mullana, Ambala, Haryana, India

Address for the Correspondence:

Dr. Neeru Bhaskar,

Department of Biochemistry,

Maharishi Markandeshwar

Institute of Medical Sciences and Research, Mullana, Ambala,

Haryana, India.

E-mail: drneerusharma77@gmail.

com

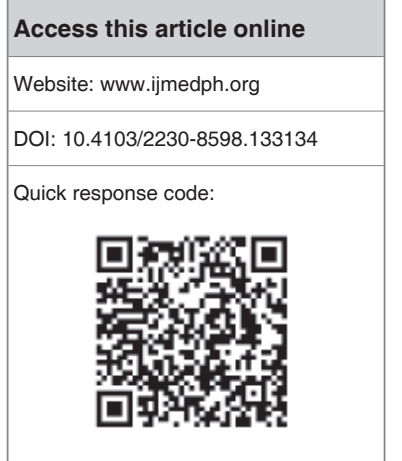

Background: Vitamin D insufficiency has been associated with several adverse health outcomes, including pregnancy outcomes, and is increasingly recognised as a public health concern. It is responsible for approximately 50,000 maternal deaths yearly worldwide, $25 \%$ of all cases of fetal growth restriction, and $15 \%$ of preterm births in developed countries. Objective: Vitamin D and magnesium sulfate act by altering the calcium levels so this study was conducted to see if vitamin D supplementation has any additive role to magnesium sulfate treatment in preeclampsia and in preventing its progression to eclampsia. Materials and Methods: This cross sectional study was conducted in the Department of Biochemistry, in collaboration with Department of Obstetrics and Gynecology, at MMIMSR, Mullana (Ambala), Haryana, India. One hundred and fifty pregnant females attending the Obstetrics clinic were selected for the study and were divided into three groups of fifty each. Group I (Control): Normotensive healthy pregnant females, Group II: Preeclamptic patients receiving magnesium sulfate therapy and Group III: Preeclamptic patients receiving magnesium sulfate therapy along with vitamin D supplementation (33000 IU once every two weeks, orally after 28 weeks up to 36 weeks). The samples were analysed for serum total calcium, ionized calcium, serum phosphorous, serum magnesium, serum albumin, serum alkaline phosphatase, serum creatinine and serum uric acid. Results: Mean levels of total calcium, ionised calcium, phosphorous, magnesium, albumin, alkaline phosphatase, creatinine and uric acid before and after delivery were calculated in all the three groups. Serum calcium (total and ionised), albumin and magnesium were decreased in preeclamptic women whereas serum phosphorous and uric acid were increased in preeclamptic. Vitamin D supplementation improved calcium status, uric acid level and albumin level were also improved. Conclusion: Vitamin D supplementation in early pregnancy improves the calcium status and reduces the severity of preeclampsia.

Key words: Calcium, magnesium, pre-eclampsia, uric acid

\section{INTRODUCTION}

Pre-eclampsia occurs in 2-5\% of pregnancies and is a major cause of perinatal and maternal morbidity and mortality. ${ }^{[1]}$ Despite the current state of perinatal care, pre-eclampsia continues to be associated with high perinatal mortality and intrauterine fetal growth retardation. While the pathophysiology of pre-eclampsia remains unclear, activation or dysfunction of the vascular endothelium in uteroplacental circulation has been proposed as a possible cause of preeclampsia. Dysfunctional endothelium in the uteroplacental circulation not only increases peripheral vascular resistance, but also influences generalized vasoconstriction via humoral factors released from the placenta. Therefore, hypertension rapidly improves after delivery. Since endothelial cells maintain the homeostasis of the coagulation cascade, the inflammatory process, and vascular tone, endothelial cell activation or dysfunction can affect thrombosis, inflammation, and hypertension. ${ }^{[2]}$ Pre-eclampsia causes changes in virtually all organ systems, most notably the cardiovascular system, renal, hematological and immunological system. Alteration in the various chemistries in mother's serum have been found to be associated with the aggravation of hypertensive complications. ${ }^{[3]}$

Low levels of vitamin D may be a risk factor for preeclampsia, and calcium supplementation in women with low calcium diets found no change in pre-eclampsia rates but did find a decrease in the rate of severe pre-eclamptic complications. Recent studies have suggested that aberration in 
calcium homeostasis is responsible for hypertension in pregnancy. The role of ionized calcium has also been suggested in membrane excitability and vasodilation. ${ }^{[4]}$ Significant changes in maternal vitamin $\mathrm{D}$ and calcium metabolism occur to provide the calcium that is needed for fetal bone mineral accretion. The pathogenesis of pre-eclampsia involves a number of biological processes that may be directly or indirectly affected by vitamin $\mathrm{D}$, including immune dysfunction, placental implantation, abnormal angiogenesis, excessive inflammation, and hypertension. ${ }^{[5-7]}$ Vitamin D has been hypothesized to influence pre-eclampsia risk. ${ }^{[8]}$ Magnesium sulfate used as treatment in pre-eclampsia increases the levels of parathyroid hormone (PTH) which promotes the conversion of 25-hydroxycalciferol to 1,25-dihydroxycalciferol and also increases placental production of 1,25-dihydroxycalciferol. As both vitamin $\mathrm{D}$ and magnesium sulfate act by altering the calcium levels so this study was conducted to see if vitamin D supplementation has any additive role to magnesium sulfate treatment in pre-eclampsia and in preventing its progression to eclampsia.

\section{MATERIALS AND METHODS}

This cross sectional study was conducted in the Department of Biochemistry, in collaboration with Department of Obstetrics and Gynecology, at Maharishi Markandeshwar Institute of Medical Sciences and Research (MMIMSR), Mullana (Ambala), Haryana, India. 150 pregnant females attending the Obstetrics clinic were selected for the study. These subjects were divided into three groups of 50 each as follows:

Group I: (Control) — Normotensive healthy pregnant females.

Group II: Pre-eclamptic patients receiving magnesium sulfate therapy.

Group III: Pre-eclamptic patients receiving magnesium sulfate therapy along with vitamin $\mathrm{D}$ supplementation (33,000 IU once every 2 weeks, orally after 28 weeks up to 36 week).

All the subjects were primigravida ( $>20$ weeks of gestation), below 35 years of age, fulfilling the criteria of severe preeclampsia, i.e., blood pressure $\geq 140 / 90 \mathrm{~mm} \mathrm{Hg}$, excretion of more than $300 \mathrm{mg}$ of urinary protein $/ 24 \mathrm{~h}$ and edema were included in our study.

\section{Exclusion criteria}

Patients with multiple pregnancy, elderly primigravidas, chronic hypertension, pre-existing renal disease and diabetes mellitus were excluded.

All the subjects received intravenous magnesium sulfate as per Zuspan regimen. ${ }^{[9]} 5 \mathrm{ml}$ of venous blood was collected under all aseptic precautions. Serum was separated and estimation of biochemical parameters was carried out within 4-6 h. The samples were analyzed for serum total calcium by $\mathrm{O}$-cresolphthalein complexone method, ${ }^{[10]}$ ionized calcium by Ion selective electrode method, ${ }^{[1]}$ serum phosphorous by Fiske and Subbarow method, ${ }^{[12]}$ serum magnesium by the Calmagite dye method, ${ }^{[13]}$ serum albumin by dye binding method, ${ }^{[14]}$ serum alkaline phosphatase by 4 -nitrophenyl phosphate, ${ }^{[15]}$ serum

creatinine by Jaffe's reaction ${ }^{[16]}$ and uric acid by Uricase method. ${ }^{[17]}$ These parameters were determined at the time of registration in the antenatal clinic, before starting magnesium sulfate therapy, either in spontaneous labor or before induction, and after giving magnesium sulfate therapy at the time of delivery. The internal control sera of two different levels were used to calibrate the instruments.

\section{Data management and statistical analysis}

During data collection completed questionnaires were checked regularly to check, to rectify any discrepancy, logical errors or missing information. The data entry was carried using Microsoft Office Excel worksheet and then exported to statistical software and analyzed using appropriate statistical tests by using Statistical Package for Social Services (SPSS version 15 for MAC IBM, Inc). Means were calculated and $t$-test was applied to find out significance level.

\section{RESULTS}

The study was conducted on 150 pregnant females attending the Obstetrics and Gynecology clinic at MMIMSR Mullana. Mean values of different parameters were calculated before and after giving magnesium sulfate therapy as shown in Tables 1 and 2 and Figures 1, 2 and 3. Significance among various parameters in different groups were also calculated [Table 3].

\begin{tabular}{lccc}
\multicolumn{3}{l}{ Table 1: Mean values of different biochemical } \\
parameters before giving magnesium sulfate therapy
\end{tabular}

Table 2: Mean values of different biochemical parameters after giving magnesium sulfate

\begin{tabular}{lccc}
\hline \multicolumn{1}{c}{ Parameters } & $\begin{array}{c}\text { Control } \\
(\boldsymbol{n}=50)\end{array}$ & $\begin{array}{c}\text { Group I } \\
(\boldsymbol{n}=50)\end{array}$ & $\begin{array}{c}\text { Group II } \\
(\boldsymbol{n}=50)\end{array}$ \\
\hline Total calcium (mg/dl) & $9.77 \pm 0.76$ & $8.4 \pm 0.73^{*}$ & $8.94 \pm 0.368^{*}$ \\
lonized calcium & $3.92 \pm 0.37$ & $3.27 \pm 0.27^{*}$ & $3.41 \pm 0.42^{*}$ \\
(mg/dl) & & & \\
Phosphorous (mg/dl) & $3.89 \pm 0.65$ & $4.64 \pm 0.87$ & $3.69 \pm 0.49$ \\
Magnesium (mg/dl) & $1.89 \pm 0.24$ & $3.66 \pm 0.64^{*}$ & $3.20 \pm 0.55^{*}$ \\
Albumin (g/dl) & $3.63 \pm 0.57$ & $3.14 \pm 0.45$ & $3.29 \pm 0.15$ \\
Alkaline phosphatase & $310.5 \pm 178.99$ & $290.16 \pm 76.69$ & $284.38 \pm 92.47$ \\
(IU/L) & & & \\
Creatinine (mg/dl) & $0.81 \pm 0.05$ & $0.81 \pm 0.06$ & $0.79 \pm 0.04^{*}$ \\
Uric acid $(\mathrm{mg} / \mathrm{dl})$ & $4.49 \pm 1.56$ & $8.32 \pm 1.98^{*}$ & $6.79 \pm 1.548^{*}$ \\
\hline
\end{tabular}




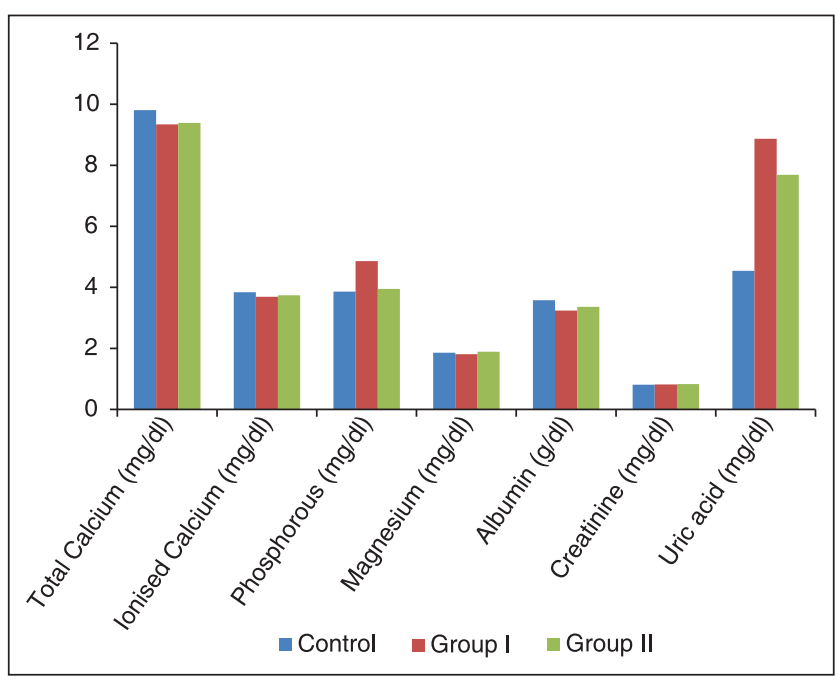

Figure 1: Serum levels of different biochemical parameters in cases and controls before delivery

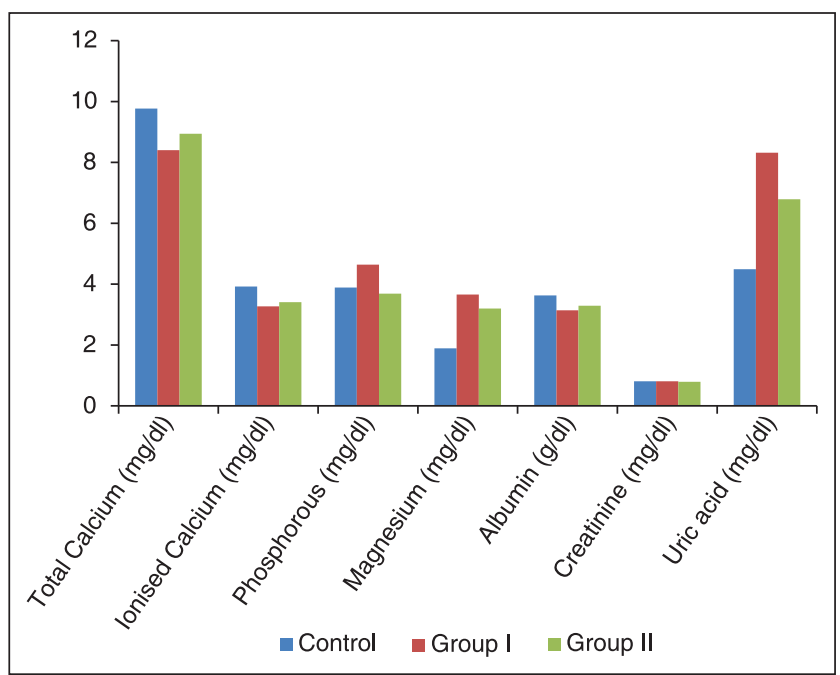

Figure 2: Serum levels of different biochemical parameters in cases and controls after delivery

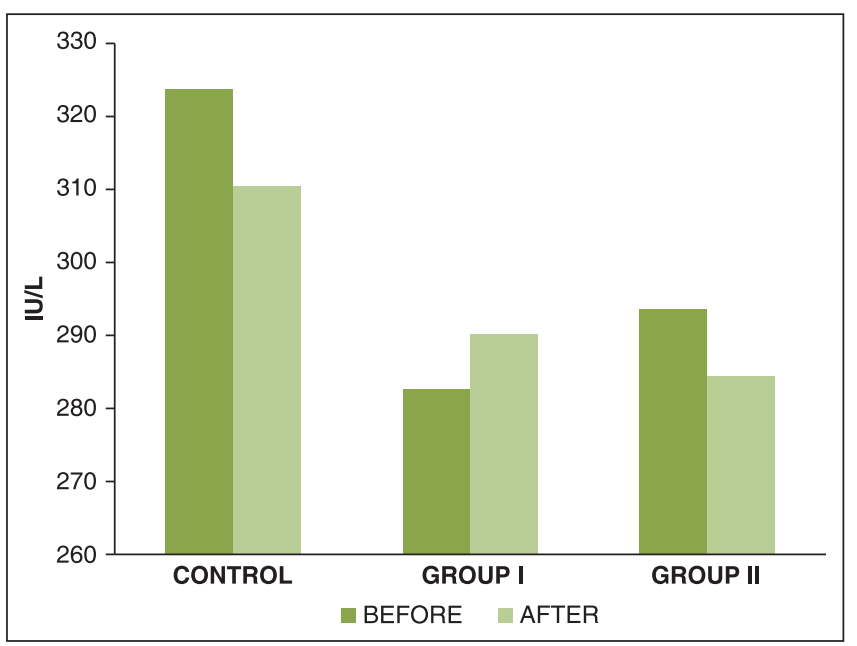

Figure 3: Serum levels of alkaline phosphatase (IU/L) in cases and controls before and after delivery

\section{DISCUSSION}

Vitamin D insufficiency has been associated with several adverse health outcomes, including pregnancy outcomes, and is increasingly recognized as a public health concern. It is responsible for approximately 50,000 maternal deaths yearly worldwide, $25 \%$ of all cases of fetal growth restriction, and $15 \%$ of preterm births in developed countries. ${ }^{[18]}$ Observational data suggest a link between low 25-hydroxyvitamin D (25(OH) D) levels - the best measure of vitamin D status in humans and an increased risk of adverse pregnancy outcomes such as gestational diabetes, preeclampsia, infections, caesarean section, and fetal growth restriction. ${ }^{[19]}$

Vitamin D has direct influence on molecular pathways proposed to be important in the pathogenesis of preeclampsia. Epidemiological studies have reported high incidence of pre-eclampsia in antenatal mothers that have disturbed calcium homeostasis. ${ }^{[4]}$ In the present study we have seen the effect of vitamin D supplementation and magnesium sulfate on calcium homeostasis in normal healthy pregnant and pre-eclamptic patients. We found a significant decrease in total calcium, ionized calcium and uric acid in both group I (calcium supplemented) and group II (calcium and vitamin D supplemented) subjects after giving magnesium sulfate. However, magnesium showed a significant increase in both the groups. Halhali et al. reported that with pre-eclampsia circulating levels of total and ionized calcium are significantly lower as compared to controls. No difference was observed in total and ionized magnesium and inorganic phosphorous. Magnesium sulfate treatment resulted in significant decrease in total and ionized calcium. ${ }^{[20]}$

Mean serum total calcium and ionized calcium levels in preeclamptic women were lower than in normal pregnant women. Some improvement was observed in the vitamin D supplemented group but the increase was not significant. The data supported the hypothesis that calcium might be a cause in the development of preeclampsia. The effect of serum calcium changes in blood pressure could be explained by the level of intracellular concentration of calcium. The increase in intracellular calcium concentration when serum calcium went lower led to constriction of smooth muscles in blood vessels and increase of vascular resistance. The present finding is similar to the previous studies. ${ }^{[21,22]}$ Women with preeclampsia have lower urinary calcium excretion, lower ionized calcium levels, higher PTH levels, and lower 1,25(OH) 2 D levels, compared with normotensive pregnant control subjects. Low plasma calcium levels induce several common mechanisms that are associated with hypertension, such as increasing renal renin and PTH levels. ${ }^{[23]}$ It is thought that placental defects that cause decreased synthesis of active vitamin $\mathrm{D}$ could be a key event in the development of this disease by contributing to decreased calcium levels. ${ }^{[24]}$ Atallah et al. found that calcium supplementation produces modest blood pressure reduction in pregnant women who are at risk for hypertensive disorder of pregnancy and in women 


\begin{tabular}{|c|c|c|c|c|c|c|}
\hline \multirow[t]{2}{*}{ Parameters } & \multicolumn{3}{|c|}{ Before } & \multicolumn{3}{|c|}{ After } \\
\hline & $\begin{array}{c}\text { Control versus } \\
\text { Group-I }\end{array}$ & $\begin{array}{c}\text { Control versus } \\
\text { Group-II }\end{array}$ & $\begin{array}{c}\text { Group-I versus } \\
\text { Group-II }\end{array}$ & $\begin{array}{c}\text { Control versus } \\
\text { Group-I }\end{array}$ & $\begin{array}{c}\text { Control versus } \\
\text { Group-II }\end{array}$ & $\begin{array}{c}\text { Group-I versus } \\
\text { Group-II }\end{array}$ \\
\hline Total calcium & $0.0012^{*}$ & $0.0002^{*}$ & 0.675 & $0.0001^{*}$ & $0.0001^{*}$ & $0.0001^{*}$ \\
\hline Ionized calcium & $0.025^{\star}$ & 0.13 & 0.450 & $<0.0001^{*}$ & $0.0001^{*}$ & $0.050^{*}$ \\
\hline Phosphorous & $0.001^{*}$ & 0.62 & $0.0002^{*}$ & $<0.0001^{*}$ & 0.085 & $0.0001^{*}$ \\
\hline Magnesium & 0.21 & 0.23 & 0.062 & $<0.0001^{*}$ & $0.0001^{*}$ & $0.0002^{*}$ \\
\hline Albumin & $0.006^{*}$ & $0.005^{\star}$ & 0.082 & $<0.0001^{*}$ & $<0.0001^{*}$ & $0.0276^{*}$ \\
\hline Alkaline phosphatase & 0.23 & 0.358 & 0.58 & 0.46 & 0.3682 & 0.744 \\
\hline Creatinine & 0.36 & 0.128 & 0.44 & 1.0 & $0.029^{*}$ & 0.0527 \\
\hline Uric acid & $0.001^{*}$ & $0.0001^{*}$ & $0.002^{*}$ & $<0.0001^{*}$ & $<0.0001^{*}$ & $0.0001^{*}$ \\
\hline
\end{tabular}

$\star P<0.05$ (statistically significant)

with low dietary calcium intake. ${ }^{[25]}$ A recent study in 274 pregnant women showed that vitamin D deficiency at or before week 22 of gestation was an independent predictor of pre-eclampsia and low vitamin D status in the neonate. Patients with $25(\mathrm{OH}) \mathrm{D}$ levels $<15 \mathrm{ng} / \mathrm{mL}$ had a 5 -fold increase in the risk of pre-eclampsia, despite receiving prenatal vitamins. ${ }^{[4]}$

Significant increase in phosphorous was observed in pre-eclamptic group as compared to control, but this increase was more in group I as compared to group II. It is known that several factors such as vitamin $\mathrm{D}, \mathrm{Ca}^{2+}, \mathrm{Mg}^{2+}$, and catecholamines etc., influence secretion of PTH, which in turn regulates activity of $1 \alpha$-hydroxylase in kidney thereby, regulating the synthesis of vitamin $\mathrm{D} \cdot{ }^{[2]}$ Fall in calcium increases PTH in kidney, decreases absorption of phosphate and increases its excretion which in turn decreases phosphate concentration in the body. ${ }^{[27]}$ Increase in calcium and decrease in phosphorous as seen in group II suggests that calcium phosphorous product remains unaltered.

The mean magnesium levels in pre-eclamptic women were lower than normal pregnant women but it was not statistically significant. Hypomagnesemia in pregnant women is associated with hemodilution, renal clearance during pregnancy and consumption of minerals by the growing fetus. ${ }^{[21]}$ Previous studies reported a relationship between hypomagnesemia and pregnancy induced hypertension. They proposed that magnesium promoted vascular muscle relaxation. Magnesium levels may have significant effects on cardiac excitability and on vascular tone, contractility and reactivity. ${ }^{[28]}$ Kister et al. observed that plasma and intracellular magnesium concentrations were significantly lower in healthy pregnant and pre-eclamptic group as compared to non-pregnant healthy females. In erythrocyte membranes, magnesium content was significantly decreased in the pre-eclamptic women as compared to healthy subjects $^{[29]}$

Significant decrease in albumin and increase in serum uric acid levels was seen in pre-eclamptic as compared to controls. Vitamin D supplemented group showed non-significant improvement in albumin and significant improvement in uric acid levels. Our results are similar to previous studies. ${ }^{[18,30]}$ The increase in serum uric acid has been primarily secondary to reduced renal urate clearance because of renal dysfunction. The elevation of uric acid in pre-eclamptic women often precedes hypertension and proteinuria. ${ }^{[18]}$ Uric acid is not only the marker for severity but also plays a role in pathogenesis. Mazzali et al. demonstrated that inhibiting the activity of uricase in rat leads to development of hypertension and renal renal changes including afferent arteriolopathy, mild tubulointerstitial fibrosis, glomerular hypertrophy and eventually glomerulosclerosis with subsequent albuminuria and proteinuria, ${ }^{[31]}$ these changes were mediated by stimulation of renin angiotensin system and inhibition of nitric oxide synthase. Soluble uric acid impairs nitric oxide generation in endothelial cells. Thus, hyperuricemia can induce endothelial dysfunction.

\section{CONCLUSIONS}

The present study proved that pre-eclampsia is associated with alteration in calcium metabolism and glomerular filtration. Though, we studied the effect of vitamin $\mathrm{D}$ on calcium metabolism during pregnancy, the limitation of our study was that vitamin $\mathrm{D}$ levels could not be estimated as facilities for its estimation were not available in our institution. Vitamin D supplementation in early pregnancy improves the calcium status and reduces the severity of preeclampsia. Further studies are needed to determine the serum vitamin $\mathrm{D}$ levels and the degree of supplementation that is required to optimize maternal and fetal outcomes. However, because vitamin $\mathrm{D}$ supplementation is simple and cost-effective with a low likelihood of toxicity, and has a beneficial effect in preeclampsia, we recommend supplementation in all pregnant women to maintain normal serum levels of $25(\mathrm{OH}) \mathrm{D}$.

\section{Ethical considerations}

The present study was approved by the Ethical Committee of MMIMSR. The approval was on the agreement that patient anonymity must be maintained, good laboratory practice, quality control ensured, and that every finding would be treated with utmost confidentiality and for the purpose of this research only. All work was performed according to the International Guidelines for Human Experimentation in Biomedical Research. ${ }^{[32]}$ Approval was obtained from the subjects by taking the informed consent. 


\section{REFERENCES}

1. Woodham PC, Brittain JE, Baker AM, Long DL, Haeri S, Camargo CA Jr, et al. Midgestation maternal serum 25-hydroxyvitamin D level and soluble fms-like tyrosine kinase 1/placental growth factor ratio as predictors of severe preeclampsia. Hypertension 2011;58:1120-5.

2. Matsubara $\mathrm{K}$, Matsubara $\mathrm{Y}$, Ito $\mathrm{M}$. The utility of vascular dysfunction studies in the prediction and prevention of preeclampsia: A historical review. Vasc Dis Prev 2009;6:163-9.

3. Bhaskar N, Kaur H, Qazi N. Serum calcium, magnesium and uric acid in preeclamptic and normal pregnancies in a tertiary care hospital: A comparative analysis. Indian J Matern Child Health 2011;13:1-7.

4. Bodnar LM, Catov JM, Simhan HN, Holick MF, Powers RW, Roberts JM. Maternal vitamin $\mathrm{D}$ deficiency increases the risk of preeclampsia. J Clin Endocrinol Metab 2007;92:3517-22.

5. Cardús A, Parisi E, Gallego C, Aldea M, Fernández E, Valdivielso JM. 1,25-Dihydroxyvitamin D3 stimulates vascular smooth muscle cell proliferation through a VEGF-mediated pathway. Kidney Int 2006;69:1377-84

6. Evans KN, Bulmer JN, Kilby MD, Hewison M. Vitamin D and placentaldecidual function. J Soc Gynecol Investig 2004;11:263-71.

7. Li YC, Kong J, Wei M, Chen ZF, Liu SQ, Cao LP. 1,25-Dihydroxyvitamin $D(3)$ is a negative endocrine regulator of the renin-angiotensin system. $J$ Clin Invest 2002;110:229-38.

8. Hyppönen E. Vitamin D for the prevention of preeclampsia? A hypothesis. Nutr Rev 2005;63:225-32

9. Cunningham F, Leveno KJ, Bloom SL, Hanth JC, editors. Hypertensive disorder in pregnancy. In: Williams Obstetrics. $22^{\text {nd }}$ ed, New York: McGraw Hill; 2005.p.787-9.

10. Connerty HV, Briggs AR. Determination of serum calcium by means of orthocresolphthalein complexone. Am J Clin Pathol 1966;45:290-6.

11. Durst RA, Anderson OS. Electrochemistry. In: Burtis CA, Ashwood ER, editors. Teitz Fundamentals of Clinical Chemistry. $5^{\text {th }}$ ed. Philadelphia: Saunders; 2002. p. 104-20

12. Atkinson $A$, Gatenby $A D$, Lowe $A G$. The determination of inorganic orthophosphate in biological systems. Biochim Biophys Acta 1973;320:195-204.

13. Krammer B, Tisdall FF. A simple technique for the determination of calcium and magnesium in small amounts of serum. J Biol Chem 1921;87:475-81.

14. Doumas BT, Peters T Jr. Serum and urine albumin: A progress report on their measurement and clinical significance. Clin Chim Acta 1997;258:3-20.

15. Bowers GN, Robert BM. Measurement of alkaline phosphatase activity in human serum. Clin Chem Acta 1975;21:1988-96.

16. Vasiliades J. Reaction of alkaline sodium picrate with creatinine: I. Kinetics and mechanism of formation of the mono-creatinine picric acid complex. Clin Chem 1976;22:1664-71.

17. Henry RJ. Estimation of uric acid. Am J Clin Pathol 1957;28:645-7.

18. Powers RW, Bodnar LM, Ness RB, Cooper KM, Gallaher MJ, Frank MP, et al. Uric acid concentrations in early pregnancy among preeclamptic women with gestational hyperuricemia at delivery. Am J Obstet Gynecol 2006;194:160.
19. Aghajafari F, Nagulesapillai T, Ronksley PE, Tough SC, O'Beirne M, Rabi DM. Association between maternal serum 25-hydroxyvitamin D level and pregnancy and neonatal outcomes: Systematic review and meta-analysis of observational studies. BMJ 2013;346:f1169.

20. Halhali A, Wimalawansa SJ, Berentsen V, Avila E, Thota CS, Larrea F. Calcitonin gene- and parathyroid hormone-related peptides in preeclampsia: Effects of magnesium sulfate. Obstet Gynecol 2001;97:893-7.

21. Punthumapol C, Kittichotpanich B. Serum calcium, magnesium and uric acid in preeclampsia and normal pregnancy. J Med Assoc Thai 2008;91:968-73.

22. Kosch M, Hausberg M, Louwen F, Barenbrock M, Rahn KH, Kisters K. Alterations of plasma calcium and intracellular and membrane calcium in erythrocytes of patients with pre-eclampsia. J Hum Hypertens 2000;14:333-6.

23. Mulligan ML, Felton SK, Riek AE, Bernal-Mizrachi C. Implications of vitamin $\mathrm{D}$ deficiency in pregnancy and lactation. Am J Obstet Gynecol 2010;202:429.e1-9.

24. Seely EW. Calciotropic hormones in preeclampsia: A renewal of interest. J Clin Endocrinol Metab 2007;92:3402-3.

25. Hofmeyr GJ, Lawrie TA, Atallah AN, Duley L. Calcium supplementation during pregnancy for preventing hypertensive disorders and related problems. Cochrane Database Syst Rev. 2010 Aug 4;(8):CD001059. doi:10.1002/14651858 CD001059.pub3.

26. Endres DB, Rude RK. Mineral and bone metabolism. In: Burtis CA, Ashwood ER, Bruns DE, editors. Teitz Textbook of Clinical Chemistry and Molecular Diagnostics. $4^{\text {th }}$ ed. New York: Elsevier; 2006. p. 1891-904.

27. Chaney SG. Vitamins and minerals: Requirement and function. In: Devlin TM, editor. Textbook of Biochemistry with Clinical Correlation. $7^{\text {th }}$ ed. New York: John Wiley \& Sons; 2011. p. 1067-71.

28. Touyz RM. Role of magnesium in the pathogenesis of hypertension. Mol Aspects Med 2003;24:107-36.

29. Kisters K, Barenbrock M, Louwen F, Hausberg M, Rahn KH, Kosch M. Membrane, intracellular, and plasma magnesium and calcium concentrations in preeclampsia. Am J Hypertens 2000;13:765-9.

30. Bainbridge SA, Roberts JM. Uric acid as a pathogenic factor in preeclampsia. Placenta 2008;29 Suppl A:S67-72.

31. Mazzali M, Hughes J, Kim YG, Jefferson JA, Kang DH, Gordon KL, et al. Elevated uric acid increases blood pressure in the rat by a novel crystalindependent mechanism. Hypertension 2001;38:1101-6.

32. World Medical Association declaration of Helsinki. Ethical principles of medical research involving human subjects world medical association available from http://www.wma.net/en/30publications/10policies/b3/

How to cite this article: Bhaskar N, Kaur H, Ishaq S, Mahajan R, Najeeb Q. Effect of vitamin D supplementation and magnesium sulfate therapy in pre-eclampsia. Int J Med Public Health 2014;4:176-80. Source of Support: Nil, Conflict of Interest: None declared. 